\title{
Erratum to: Psychosocial acceptance of cleft patients: has something changed?
}

\author{
Niels Christian Pausch ${ }^{1}$ Karsten Winter ${ }^{2} \cdot$ Dirk Halama $^{1} \cdot$ Christian Wirtz $^{3}$. \\ Vedat Yildirim $^{1} \cdot$ Nattapong Sirintawat $^{1}$
}

Published online: 11 August 2015

(C) Springer-Verlag Berlin Heidelberg 2015

Erratum to: Oral and Maxillofacial Surgery

DOI 10.1007/s10006-015-0518-1

The original version of the above article contained a mistake in the presentation of one of the author names. Instead of Sirintawat Nattapong, it should be presented as Nattapong Sirintawat.

The online version of the original article can be found at http://dx.doi.org/ 10.1007/s10006-015-0518-1.

Niels Christian Pausch

niels.pausch@medizin.uni-leipzig.de

1 Department of Oral, Craniomaxillofacial and Facial Plastic Surgery, Faculty of Medicine, University Hospital of Leipzig,

Leipzig, Germany

2 Translational Centre for Regenerative Medicine (TRM), University of Leipzig, Leipzig, Germany

3 Karl-Olga-Hospital Stuttgart, Stuttgart, Germany 